\title{
Aplicação de PBL on-line em cursos da área de computação durante a pandemia de COVID-19
}

\author{
Davy Gomes \\ Instituto Federal da Bahia \\ Feira de Santana, Bahia, Brasil \\ davymatos01@gmail.com \\ Fernanda Santana \\ Instituto Federal da Bahia \\ Feira de Santana, Bahia, Brasil \\ fernandacastelo@ifba.edu.br
}

\author{
Luciano Silva \\ Instituto Federal da Bahia \\ Feira de Santana, Bahia, Brasil \\ teleslu9@gmail.com \\ Igo Amauri Luz \\ Instituto Federal da Bahia \\ Santo Antônio de Jesus, Bahia, Brasil \\ igo.luz@ifba.edu.br
}

O elevado número de casos de pessoas contaminadas pelo novo coronavírus em diferentes localidades geográficas tem gerado uma crise sanitária e humanitária no mundo [5]. Medidas estão sendo tomadas para diminuição das taxas de transmissão do vírus, dentre elas a suspensão das atividades presenciais nas instituições de ensino. As organizações educacionais necessitaram reorganizar as suas atividades para um contexto remoto e um dos desafios que surgiram foi como manter o engajamento dos estudantes em suas atividades formativas em um cenário que exige adaptação à nova maneira de se posicionar em salas, agora virtuais, e aos novos espaços de trabalho, geralmente suas residências.

Há outras questões de forte impacto que podem resultar em menor motivação do aluno no processo de ensino-aprendizagem, como aquelas relacionadas à saúde mental. Estudos iniciais relatam uma prevalência elevada de sintomatologia depressiva e ansiosa autorrelatada de moderada a grave entre o público em geral devido ao COVID-19 [7] e outros apontam que é esperada uma elevação dos níveis de estresse para os estudantes do ensino superior devido à adoção emergencial da aprendizagem remota [4].

Nesse contexto, com a pretensão de possibilitar aos alunos do Instituto Federal da Bahia uma experiência na qual possam se reaproximar da instituição e assumam uma postura ativa diante dos conhecimentos essenciais para a sua formação, considerou-se utilizar a metodologia PBL (Problem Based Learning) como uma maneira de tornar a aprendizagem dos estudantes mais eficiente. Sua aplicação em componentes ofertados para cursos superiores da área de computação nos campus em Feira de Santana e Santo Antônio é uma prática inovadora na instituição e desconhecida pela maioria dos estudantes, mas percebida pelos autores deste trabalho como estratégia para manter os estudantes motivados e habilitados a desenvolver autonomia na busca pelo conhecimento em seus novos espaços de aprendizagem.

O projeto descrito neste trabalho é dividido em três etapas: planejamento, execução e avaliação da aplicação do PBL online. O

Fica permitido ao(s) autor(es) ou a terceiros a reprodução ou distribuição, em parte ou no todo, do material extraído dessa obra, de forma verbatim, adaptada ou remixada, bem como a criação ou produção a partir do conteúdo dessa obra, para fins não comerciais, desde que sejam atribuídos os devidos créditos à criação original, sob os termos da licença CC BY-NC 4.0.

EduComp'21, Abril 26-30, 2021, Jataí, Goiás, Brasil (On-line)

(C) 2021 Copyright mantido pelo(s) autor(es). Direitos de publicação licenciados à Sociedade Brasileira de Computação (SBC). planejamento, já iniciado, consiste em atividades como selecionar os cursos e turmas que deveriam participar do estudo e a criação de situações problemas a serem apresentados aos grupos tutoriais. A fase de execução, também já iniciada, permitiu a aplicação do PBL no componente curricular Arquitetura de Computadores e Software Básico e no componente extracurricular Desenvolvendo Games com Godot Engine, disponibilizado para estudantes de cursos superiores do IFBA. Os estudantes foram divididos em grupos tutoriais, mediados por um docente com experiência na aplicação de PBL em cursos presenciais, e ferramentas digitais foram utilizadas para suporte na execução remota, com destaque para o Microsoft Teams, uma plataforma unificada de comunicação e colaboração da Microsoft [1].

Outras atividades de planejamento e execução serão realizadas, especialmente porque se pretende aplicar a metodologia em mais turmas da área de computação do Instituto. Nesse contexto, a etapa de avaliação dos experimentos é essencial, pois possibilitará analisar se, de fato, o objetivo do projeto foi alcançado. Para subsidiar a avaliação, pretende-se construir instrumentos diagnósticos que possam trazer dados que representem as opiniões dos membros do grupo tutorial sobre a experiência, bem como dados sobre condições sócios-econômicas e emocionais destes estudantes para. Formulários estão sendo criados com base em outros estudos [2, 3, 6] e serão disponibilizados aos participantes da pesquisa para preenchimento online.

Durante o desenvolvimento do trabalho, tem-se percebido a necessidade de refletir sobre diferentes aspectos, entre eles: o ambiente virtual de aprendizagem possibilita de maneira satisfatória a execução remota do PBL? A conectividade com a Internet impactou o experimento? Foi possível estabelecer relacionamento entre pares e profundidade na discussão dos temas? Compreender estes e outros critérios serão essenciais para analisar se a aplicação da metodologia PBL foi realizada de maneira adequada e se resultou em uma aprendizagem efetiva mesmo diante dos desafios que a pandemia de COVID-19 tem imposto.

\section{AGRADECIMENTOS}

Os autores agradecem ao Instituto Federal da Bahia (IFBA) pelo apoio financeiro. 


\section{REFERÊNCIAS}

[1] 2021. Microsoft Teams $\mid$ Aplicativo de Chat Interno| Trabalho Remoto. https: //www.microsoft.com/pt-br/microsoft-teams/group-chat-software. (Accessed on 04/13/2021).

[2] Abdulrahman Alduraywish, M.O. Mohager, Mohammed Alenzi, Abdelsalam Nail, and Alfatih Aljafari. 2017. Evaluation of students' experience with Problem-based Learning (PBL) applied at the College of Medicine, Al-Jouf University, Saudi Arabia. Journal of the Pakistan Medical Association 67 (12 2017), 1870-1873.

[3] Michele Angelo, Angelo Loula, Fabiana Bertoni, and José Santos. 2014. Aplicação e Avaliação do Método PBL em Um Componente Curricular Integrado de Programação de Computadores. Revista de Ensino de Engenharia, 33 (10 2014), 31-43. https://doi.org/10.15552/2236-0158/abenge.v33n2p31-43

[4] Nicholas Grubic, Shaylea Badovinac, and Amer M Johri. 2020. Student mental health in the midst of the COVID-19 pandemic: A call for further research and immediate solutions. International fournal of Social Psychiatry 66, 5 (2020), 517-518. https://doi.org/10.1177/0020764020925108 arXiv:https://doi.org/10.1177/0020764020925108 PMID: 32364039.

[5] Nísia Lima, Paulo Buss, and Rômulo Paes-Sousa 2020. A pandemia de COVID19: uma crise sanitária e humanitária. Cadernos de Saúde Pública 36 (01 2020). https://doi.org/10.1590/0102-311x00177020

[6] Gustavo Romão, Reinaldo Bestetti, and Lucélio Couto. 2020. Aplicação do PB Clínico na Atenção Primária em Cursos de Medicina. Revista Brasileira de Educação Médica 44 (01 2020). https://doi.org/10.1590/1981-5271v44.4-20200115

[7] Cuiyan Wang, Riyu Pan, Xiaoyang Wan, Yilin Tan, Linkang Xu, Cyrus S. Ho, and Roger C. Ho. 2020. Immediate Psychological Responses and Associated Factors during the Initial Stage of the 2019 Coronavirus Disease (COVID-19) Epidemic among the General Population in China. International fournal of Environmental Research and Public Health 17, 5 (2020). https://doi.org/10.3390/ijerph17051729 